\title{
BAG revidiert jahrzehntelange Rechtsprechung
}

\section{Ergänzung im DRK-Gesetz ermöglicht unbefristete Gestellung von Rotkreuzschwestern}

") Das Bundesarbeitsgericht (BAG) hat am 21. Februar 2017 entschieden, dass Rotkreuzschwestern, die bei Gestellungsvertragspartnern, d.h. in Krankenhäusern und anderen Einrichtungen des Gesundheitswesens eingesetzt werden, unter die Regelungen des Arbeitnehmerüberlassungsgesetzes (AÜG) fallen. Auf rund 18.000 der bundesweit 25.000 Rotkreuzschwestern trifft dies zu. „Wir bedauern, dass das
BAG nach mehr als 60 Jahren gleichlautender Rechtsprechung seine bisherige Rechtsauffassung nicht vollumfänglich aufrechterhalten hat", sagt Generaloberin Gabriele Müller-Stutzer, Präsidentin des Verbandes der Schwesternschaften vom DRK e.V. (VdS).

Auch wenn die Entscheidung des BAG zunächst keine unmittelbaren Auswirkungen auf den Arbeitsplatz von gestellten Rotkreuzschwestern

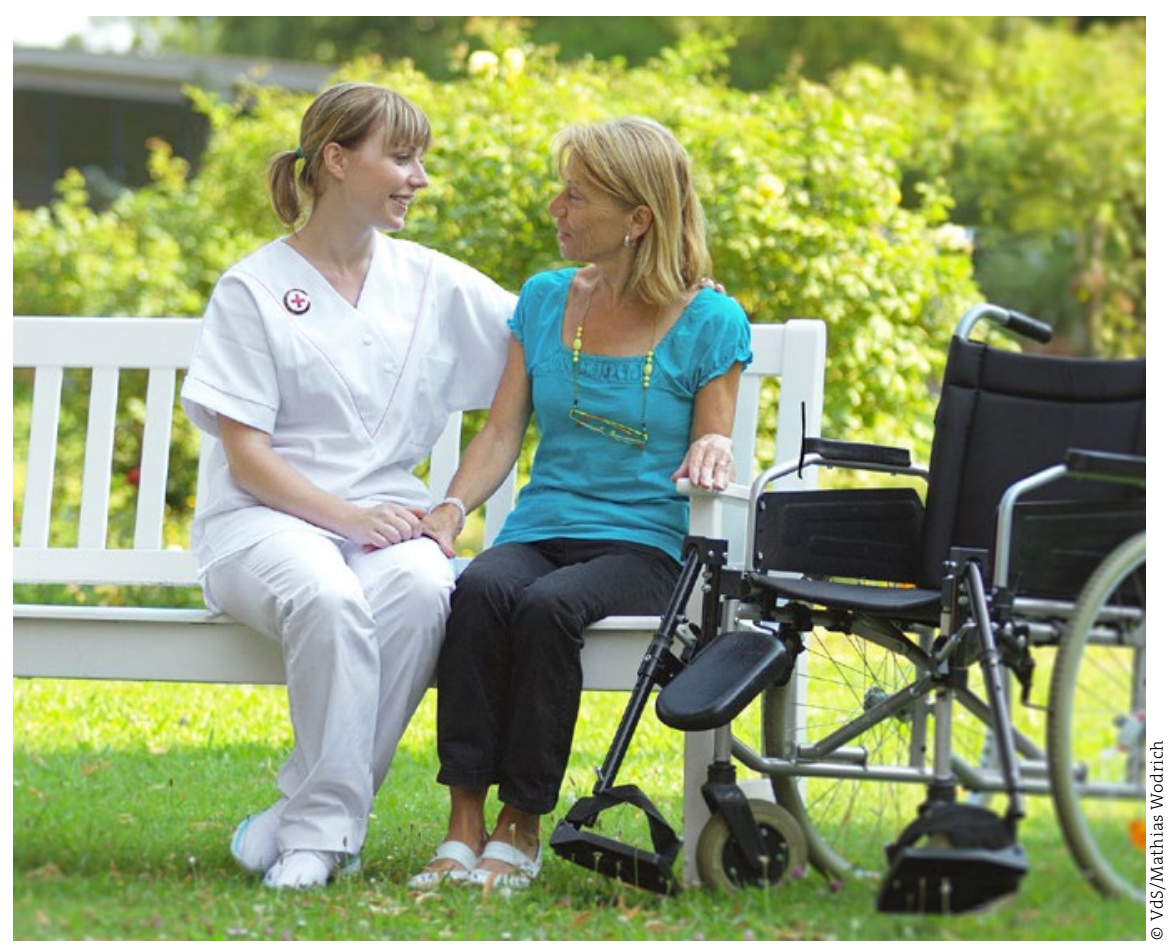

hat, bedeutet die Umsetzung der Vorgaben des AÜG für die DRK-/BRKSchwesternschaften einen erheblichen administrativen Mehraufwand (Einholen der Erlaubnis zur Arbeitnehmerüberlassung, namentliche Meldung der gestellten Rotkreuzschwestern an die Agentur für Arbeit etc.).

Der Widerstand des VdS und des DRK richtet sich primär gegen die uneingeschränkte Anwendung des AÜG auf gestellte Rotkreuzschwestern, da sie sich weder formal noch inhaltlich als „Leiharbeitnehmerinnen“ verstehen. Das Gros der Rotkreuzschwestern befindet sich in einem unbefristeten Einsatz bei Gestellungsvertragspartnern und gehört zur "Stammbelegschaft" der Gesundheits- und Pflegeeinrichtungen.

Ein wichtiger Kritikpunkt, die Überlassungshöchstdauer von 18 Monaten scheint inzwischen vom Tisch zu sein: Die Bundesregierung und namentlich die Bundesministerin für Arbeit und Soziales, Andrea Nahles, hat eine zügige Änderung des DRK-Gesetzes zugesagt, der zufolge auch künftig die Gestellung von Mitgliedern einer DRK-Schwesternschaft unbefristet ermöglicht werden kann. Damit wäre sichergestellt, dass Rotkreuzschwestern auch weiterhin dauerhaft an einem Einsatzort tätig sein können.

\section{www.rotkreuzschwestern.de}

\section{Pflege in Bewegung}

\section{Bundesweite „Gefährdungsanzeige“ soll Politik wachrütteln}

") Für den 12. Mai hat die Initiative „Pflege in Bewegung“ zu einem Aktionstag in Berlin aufgerufen. Der Verein hat bundesweite „Gefährdungsanzeigen“ aufgesetzt, die Personalmangel, inakzeptable Arbeitsbedingungen und miese Entlohnung der beruflich Pflegenden anprangern.

Kritisiert werden auch die schlechten Rahmenbedingungen für pflegende Angehörige. Unterstützer können Flyer unterschreiben und an den Verein senden. Die Unterschriften sollen am Aktionstag Bundesgesundheitsminister Hermann Gröhe übergeben werden. „Auf Grund des demographischen Wandels und des sich verschärfenden Pflegenotstandes ist es an der Zeit, die Politik zum sofortigen Handeln zu bewegen“, so Roger Konrad, Vorsitzender von „Pflege in Bewegung“.

Unterstützt wird die Initiative unter anderem von der rheinland-pfälzischen Pflegekammer. Präsident Dr. Markus Mai: „Wir sind stolz, Unterstützer und Wegbegleiter dieser jun- gen Bewegung von professionell Pflegenden und pflegenden Angehörigen zu sein." Deshalb unterstütze man die Kampagne zur Gefährdungsanzeige, die in weiten Teilen zu den kammereigenen Forderungen passe. Weitere Wegbegleiter sind einige Städte des bundesweiten Personenbündnisses „Pflege am Boden“ und die Siegener Initiative „Wa(h)re Gesundheit - da hilft nur noch beten?".

\section{www.pflegeinbewegung.de}

